\title{
The Factor(s) Influencing Male Involvement in Family Planning- Findings from a Rural Community in South West, Nigeria
}

\author{
Olusola Fajobi ${ }^{1, \text { * }}$, Damola Adeola Fajobi ${ }^{2}$, Olukemi Titilope Olugbade ${ }^{1}$, Samuel Anu Olowookere ${ }^{3}$ \\ ${ }^{1}$ Department of Community Health, Obafemi Awolowo University Teaching Hospitals Complex, Ile-Ife, Nigeria \\ ${ }^{2}$ APIN Public Health Initiative, Osogbo, Nigeria \\ ${ }^{3}$ Department of Community Health, Obafemi Awolowo University, Ile-Ife, Nigeria
}

Email address:

sholex111@gmail.com (O. Fajobi)

${ }^{*}$ Corresponding author

\section{To cite this article:}

Olusola Fajobi, Damola Adeola Fajobi, Olukemi Titilope Olugbade, Samuel Anu Olowookere. The Factor(s) Influencing Male Involvement in Family Planning- Findings from a Rural Community in South West, Nigeria. Central African Journal of Public Health.

Vol. 7, No. 3, 2021, pp. 94-101. doi: 10.11648/j.cajph.20210703.12

Received: April 16, 2021; Accepted: May 5, 2021; Published: May 14, 2021

\begin{abstract}
The drive to include men in family planning programming in one part can increase contraceptive prevalence and also reduce the unmet need for family planning especially in Africa especially sub-Saharan Africa, where 2015 millennium development goals in reproductive health were not achieved, however concerted efforts to achieve the sustainable development goals is ongoing. The contraceptive prevalence in Nigeria reported to be $17 \%$ in 2018 is less than the average of $55 \%$ in sub-Saharan Africa and global average of $76 \%$. This low adoption of contraceptive has been linked to increased maternal mortality in the region. We conducted a descriptive cross-sectional study which examined the role of 464 married men, in family planning in Gambari, a rural settlement in Oyo state, South-West Nigeria. The objective of the study was to determine the knowledge, attitude and use of modern contraceptive methods by respondents and their spouses and to identify factors which influence the adoption of family planning methods by men. The mean age of respondents was 42 years, with their age ranging from 20 to 85 years. The Contraceptive method most respondents were aware of, was the injectable $(62.5 \%)$ followed by the condom (44.8\%). A total 80.8\% (375) of men had overall poor knowledge of contraceptive methods, while 19.2\% (89) had good knowledge. There was a statistically significant relationship between couples' discussion of family planning and spousal contraceptive use $(\chi 2=123, \mathrm{p}<0.0001)$. Multivariate analysis showed that men with at least secondary education had a better knowledge, attitude and were more likely to have used modern contraception than those with only primary or no education. The study concluded that with better knowledge about contraceptives, men can enhance adoption of family planning, increase contraception uptake and match their attitudes with corresponding action.
\end{abstract}

Keywords: Child Limiting, Child Spacing, Contraceptives, Married Men, Family Planning

\section{Background}

The interest in men's involvement in reproductive health has continued to increase since the International Conference on Population and Development (ICPD) in 1994. [1] Despite this, low levels of men's involvement in family planning services continues to be a major barrier to achieving a high rate of use of modern contraceptive in sub-Saharan Africa. [2] The improvement of men's access to effective contraceptive methods can contribute significantly to community and country's reproductive health outcomes. It can also improve a nation's health status and economic well-being. [3] The drive to include men in family planning programming in one part can increase contraceptive prevalence and also reduce the unmet need for family planning. [3]

The use of modern contraceptive device in sub-Saharan Africa has been reported to be lower than other regions of the world. [4] This low adoption of contraception can be linked to increased maternal mortality in the region. [5] Globally, About 295,000 women died during and following pregnancy and 
childbirth in 2017 , and about $66 \%$ of these preventable deaths occurred in sub-Saharan Africa. [5] The contraceptive prevalence in Nigeria which was reported to be $17 \%$ in 2018 is much less than the sub-Saharan Africa average of 55\% and global average of $76 \%$. [4, 6] The reality may be worse with the fact that the modern contraceptive rate in women in Nigeria is only $12 \%$. [6]

The unmet need for family planning in Nigeria which is strongly associated with unwanted pregnancies has been the highest in the region since 2010, [3] and remains high with a report of $19 \%$ in 2018. [6] The trend of this indicator over the last 20 years has not been satisfactory. A reduction from $20.2 \%$ in 2008 to $16.1 \%$ in 2013 was not sustained despite the huge amount of resources invested into family planning programs and other interventions. [7, 8]

Unmet need for family planning has become one of the global indicators to measure the uptake of family planning. [9] Unmet need has been measured through women; however, it is a well-known fact in Africa, that men are the main decisions makers in their families. The reasons range from religion to cultural norm and greater economic power by men in many African societies. [1, 10, 11] Evidence indicates that male involvement can lead to contraceptive uptake and thereby reduce the unmet need for family planning in many societies. $[1,10,11]$

Low family planning adoption over the years has been a major correlate of persistently high maternal mortality rates in Sub-Saharan Africa. [12] The World Health Organization (WHO) estimated that sub-Saharan Africa had contributed the highest proportion (56\%) of 287,000 global maternal deaths in 2010. Globally, there were $40 \%$ of all pregnancies or 85 million pregnancies were unintended in 2012. [13]. In addition, the sub-Saharan African region will have the greatest increase in population in the next 50 years, [3] and with the current low levels of family planning adoption, population increase may lead to increasing poverty and family conflicts over contraceptive use, both of which may work together to produce worse health outcomes for women and children in the future. [14]

A lot of studies have focused on the female sex for improving the uptake of family planning services. [7, 10, 15] It has also been documented in Africa, that most men have preference for a big family, therefore, in most marital relationships, the consent and express approval of the male partner is often needed for women's uptake of family planning services because most women do not feel empowered to make decisions pertaining to family planning. $[1,10]$ Men's acceptance of family planning cannot be independent of the depth of their knowledge about contraceptive methods. [1] Furthermore, if studies have shown that women's choices are affected my men's preference, it is therefore imperative to determine men's awareness, preference and attitude towards the use of contraception as different from women's views. This may be the most important research towards advancing the uptake of family planning in sub-Saharan Africa.

The 2030 Agenda for Sustainable Development has affirmed under target 3.7 to ensure by 2030, the integration of reproductive health into national health strategies in other to achieve universal access to sexual and reproductive health services including family planning. [4] Many family planning clinics in sub-Saharan Africa including Nigeria are mostly focused on women and this is also more pronounced with the fact that most policy review or studies on family planning have put women as the focus. [2]

The adoption of family planning has been measured in different countries through contraceptive prevalence, unmet need for family planning and demand for family planning satisfied by modern methods. [4, 6] There are some differences in these measurements which relates to the inclusion of the masculine gender in measurement of contraceptive prevalence. While the United Nations included contraceptive use by either spouse, Nigerian Demographic health survey uses only the feminine gender. [4, 6] This difference points to a systematic or cultural exclusion of men from contraceptive use.

The answer to low family planning uptake in sub-Saharan Africa, as evidenced by low contraceptive prevalence and high unmet need for family planning may lie in involving the male gender rather than focusing on the female gender only. The extent of male involvement in family planning decision making has been studied by some authors, who found out that older aged men, the lack of adequate communication between spouses, ignorance of modern contraceptive devices, and lack of access to services were among the reasons why men have not been adequately involved in family planning issues. [1, 16] Other reasons include misconceptions about family planning, and a combination of a good attitude but poor practice of family planning. Some studies also reported outright rejection of modern family planning methods by some men. [2]

The demand and supply factors have been presented as the two major factors working together in determining family planning adoption. [7] The demand factors refer to the realization of a family for the need for spacing pregnancy or limiting the number of children. [7] The supply side is majorly about the availability of contraceptive methods or reproductive health services where people can access all forms of family planning which they may need within a reasonable time. [17, 18] Both the demand and the supply side of contraceptive use can target men.

Targeting men and women in programs can have a great impact on contraceptive prevalence compared to targeting only women, or neglecting the role of men in family planning adoption especially in rural areas of sub-Saharan Africa. [11, 19] Men can be the major targets of radio adverts in a bid to increase their knowledge on modern contraceptive devices, and also, they can be encouraged to discuss more with their wives and also use contraceptive devices when needed. [16] In addition, other studies had suggested that advocacy efforts should target opinion leaders of communities who are usually male, for the purpose of influencing male heads of families in their community. [1]

This study examined the role of married men in family 
planning uptake. It looked at the knowledge, attitude and use of modern contraceptive methods by respondents and their spouses and the factors which influence the adoption of family planning by men. The findings from this survey may play a role in shaping policies to drive family planning programmes in rural communities, with the aim of increasing men's participation and adoption in future.

\section{Methods}

\subsection{Study Location}

The study was carried out at Gambari village, a rural settlement in Surulere Local Government of Oyo state, Nigeria. The community is close to both the urban Kwara state capital city of Ilorin and a semi-urban town of Ogbomoso in Oyo State. The town had a total population of 8,416 comprising of 3998 males and 4418 females as documented in 2006 National Population Census. [20] It has a government-owned primary health care centre, a private clinic, and a state-owned radio station serving the community. All Nigerian ethnic groups are represented in the settlement although more than $80 \%$ are Yoruba. The religions being practiced are Christianity and Islam with some traditional worshippers.

\subsection{Study Design}

A cross-sectional descriptive study design was used to assess the role of men in family planning in Gambari Village, Surulere Local Government Area, Oyo State, Nigeria.

\subsection{Study Population}

Study population consists of married men in Gambari Village, Surulere Local Government Area, Oyo State, Nigeria.

\subsection{Sample Size Determination}

The sample size of respondents was obtained by obtained using the Cochran and Leslie-Fischer formula for studying proportions with populations less than 10,000. [21]

$$
n=\frac{z^{2} p q}{d^{2}} \ldots
$$

$\mathrm{d}$ - degree of accuracy desired $=0.05$

$\mathrm{z}$ - standard normal deviate $=1.96$

$\mathrm{p}=$ prevalence of $15.5 \%$ (Proportion of men who followed their wives to a family planning clinic in Osogbo Osun State) [1]

$$
\mathrm{n}=\frac{1.96^{2} \times 0.155 \times(1-0.1555)}{0.05^{2}}=202 .
$$

A clustering factor of 2 was introduced, which increase the sample size to 404 and a non-response rate of $10 \%$ gave a minimum sample size of 423 . A total of 475 men participated in the study and 11 questionnaires were discarded because of incomplete entry which left a total of 464 participants for the analysis.

\subsection{Sampling Technique}

A 2-stage sampling was used to select respondents. Gambari village was divided into 20 settlements, household listing was done for each settlement and proportionate number of households was selected for each settlement through simple random sampling by balloting. Questionnaires were administered to the male head of households. Households with female heads were excluded from the study.

\subsection{Data Collection Technique}

A semi structured interviewer-administered questionnaire was used to collect information from respondents by trained research assistants with a minimum of bachelor's degree. The questionnaire was translated to Yoruba, the local language of the community to facilitate understanding and consistency in translation among research assistants.

The questionnaire had four sections which included the socio-demographic characteristics, awareness and knowledge of family planning methods, attitude towards use of modern contraceptives and actual use and practice of family planning by the men and their spouses. Pre-testing of the questionnaire was carried out on 50 respondents in Igbon town, a neighboring community with similar characteristics to Gambari village.

\subsection{Data Processing and Analysis}

Information from questionnaires was checked for completeness and data entry was done with Microsoft Excel software, cleaned, and exported into Stata software version 14 for data analysis. Respondents level of knowledge was assessed by assigning 1 or 0 score to every correct or wrong answer to knowledge questions on types of modern contraceptives known, knowledge of side effects and causes of contraceptives failure. Respondents with knowledge score of 6 and above were categorized as having good knowledge, while those who scored less than 6 were classified as having poor knowledge of contraceptives.

Attitude was assessed with a 5-point Likert scale and scores of up to 5 were assigned to each of 9 attitudinal questions. An individual score of 31 or more was classified as positive attitude while, those who scored 30 or less were assigned negative attitude. Descriptive statistics, chi square test statistics and binary logistic regression analysis were employed in the analysis. Level of statistical significance was set at $\mathrm{p}$-value less than 0.05 .

\subsection{Ethical Issues}

Ethical approval to carry out the research was obtained from the Ethical and Research Review committee of LAUTECH Teaching Hospital Ogbomoso. Permissions were sought and obtained from Community leaders and Local government health department. Informed consent was obtained from all participants and confidentiality of participants was always maintained. 


\section{Results}

\subsection{Sociodemographic Characteristics of Respondents}

A total of 464 completed questionnaires were analyzed for the study. The age of respondents ranged from 20 to 85 years with a mean age of 42 years and standard deviation of 11.9 years. The age group $30-39$ years constitute about $35 \%$ of respondents, while $80 \%$ of respondents were between 30 and 59 years old. About 12.5\% (58) of the population have no formal education, $15.5 \%$ (72) have tertiary education and others have either have either Primary or secondary education as their highest educational attainment. Ninety-four percent of respondents were of the Yoruba ethnic group, nearly two-thirds of the respondents were Christians and about one-third being Muslims. Most of the respondents (35.8\%) were artisans in different trades, followed closely by farmers (24.1\%). 80\% (372) of respondents practice monogamy while about $20 \%$ (92) practice polygamous marriage (Table 1).

Table 1. Socio-demographic characteristics of respondents in Gambari Village, Surulere Local Government Area, Oyo State, Nigeria.

\begin{tabular}{ll}
\hline Characteristics & Frequency $\mathbf{( \% )} \mathbf{N}=\mathbf{4 6 4}$ \\
\hline AGE & $44(9.5)$ \\
$<30$ & $162(34.9)$ \\
$30-39$ & $126(37.2)$ \\
$40-49$ & $84(18.1)$ \\
$50-59$ & $48(10.3)$ \\
$60+$ & $58(12.5)$ \\
EDUCATION ATTAINED & $150(32.3)$ \\
No Formal & $184(39.7)$ \\
Primary & $72(15.5)$ \\
Secondary & \\
Tertiary & $292(62.9)$ \\
RELIGION & $170(36.6)$ \\
Christianity & $2(0.4)$ \\
Islam & \\
Traditional & $120(25.9)$ \\
OCCUPATION & $282(60.8)$ \\
Non-skilled & $62(13.4)$ \\
Semi-skilled & \\
Skilled & $436(94.0)$ \\
TRIBE & $8(1.6)$ \\
Yoruba & $20(4.4)$ \\
Hausa &
\end{tabular}

** Igede, Igara and Benue tribe.

\subsection{Knowledge of Modern Contraceptive Methods}

Ninety-five percent (442) of respondents have heard about modern contraception while $4.7 \%$ (22) of the study population have not heard about it. The contraceptive method most mentioned was the injectables $(62.5 \%)$ followed closely by male condoms (44.8\%) and pills (40.5\%). The least known methods were the emergency contraception, vasectomy and lactational amenorrhea (LAM) methods. There was no mention of female Condom by the respondents (Table 2).

Table 2. Awareness of Contraceptive Methods among Married Men in Gambari Village, Surulere Local Government Area, Oyo State, Nigeria.

\begin{tabular}{lll}
\hline Types of Contraceptive Method & Freq. $\mathbf{N}=\mathbf{4 6 4}$ & Percentage (\%) \\
\hline Injectable & 290 & 62.5 \\
Male Condom & 208 & 44.8 \\
Pills & 188 & 40.5 \\
IUCD & 84 & 18.1 \\
Traditional Method & 84 & 18.1 \\
BTL & 32 & 6.9 \\
Implants & 22 & 4.7 \\
Calendar method & 20 & 4.3 \\
LAM & 14 & 3 \\
Vasectomy & 10 & 2.2 \\
Emergency Pills & 6 & 1.3 \\
Female Condom & 0 & 0 \\
\hline
\end{tabular}




\subsection{Awareness of Side-Effect and Causes of Contraceptive Failure}

Forty-eight percent of respondents are aware that there are side effects associated with the use of contraceptives, however, less than $10 \%$ of then were aware of breast tenderness, delayed childbirth or bleeding being known side-effects. The most common side effects of contraceptives known to respondents were menstrual changes $(18 \%)$ and weight gain $(16 \%)$. Twenty-three percent (91) men think incorrect use of contraceptive devices can cause contraceptive failure, while inconsistent use and incorrect timing can cause contraceptive failure according to $17.9 \%$ and $14 \%$ of men respectively. About $6 \%$ of men believed that the cause of contraceptive failure that be divine.

\subsection{Attitude Towards Family Planning}

We found out that 73.7 percent of respondents approved of attending family planning clinic with their wives while 20.3 percent of them disapproved it. Fifty-nine percent of them agreed that family planning is not a woman-only affair while 47.4 percent agreed that a man should take up family planning if a spouse fails to. $72.4 \%$ of respondents also believe that family planning will help them live a more productive life while about 1 in 3 men prefer traditional family planning methods to modern methods (Table 3 ).

\subsection{Overall Knowledge and Attitude Towards Family Planning}

Based on all questions assessing knowledge and computed for each respondent, $80.8 \%$ (375) of men had poor knowledge, while $19.2 \%$ (89) had good knowledge of contraceptive devices, their side effect and causes of failure. With regards to attitude, $55.2 \%$ (256) of the men had a positive attitude, while $44.8 \%$ (208) had a negative attitude towards family planning.

Table 3. Attitudes towards Family Planning among Married Men in Gambari Village, Surulere Local Government Area, Oyo State, Nigeria.

\begin{tabular}{|c|c|c|c|}
\hline Selected attitude related questions & $\begin{array}{l}\text { Agree Frequency n } \\
(\%)\end{array}$ & $\begin{array}{l}\text { Disagree } \\
\text { Frequency N (\%) } \\
\end{array}$ & $\begin{array}{l}\text { Undecided } \\
\text { Frequency N (\%) }\end{array}$ \\
\hline Consistent use of contraceptives prevents unwanted pregnancy & $366(78.9)$ & $62(13.3)$ & $36(7.8)$ \\
\hline Family planning is a woman only affair. & $162(35)$ & $274(59.4)$ & $26(5.6)$ \\
\hline Condoms can prevent STI and pregnancy & $376(81)$ & $36(7.7)$ & $52(11.2)$ \\
\hline Men should go with their wives to family planning clinic. & $342(73.7)$ & $94(20.3)$ & $28(6)$ \\
\hline Women should have as many children as possible & $174(37.5)$ & $44(9.5)$ & $246(53.0)$ \\
\hline Men should take up family planning if their spouse refuses to take it up. & $220(47.4)$ & $178(38.4)$ & $66(14.2)$ \\
\hline Couples should practice family planning to live a more productive life. & $336(72.4)$ & $60(12.9)$ & $68(14.7)$ \\
\hline Men should practice traditional family planning more than modern family planning. & $144(31.0)$ & $160(34.5)$ & $160(34.4)$ \\
\hline
\end{tabular}

Table 4. Association between socio-demographic characteristics and use of contraceptives among Married Men in Gambari Village, Surulere Local Government Area, Oyo State, Nigeria.

\begin{tabular}{|c|c|c|c|c|}
\hline \multirow{2}{*}{ Variable } & \multicolumn{2}{|c|}{ Ever used contraceptive $N=464$} & \multirow{2}{*}{$\chi^{2}(\mathrm{df})$} & \multirow{2}{*}{ P-value } \\
\hline & Yes n (\%) & No n $(\%)$ & & \\
\hline \multicolumn{5}{|l|}{ Age Group } \\
\hline Less than 50 & $106(31.9)$ & $226(68.1)$ & \multirow[t]{2}{*}{19.1} & \multirow[t]{2}{*}{$<0.0001$} \\
\hline 50 and above & $16(12.1)$ & $116(89.9)$ & & \\
\hline \multicolumn{5}{|l|}{ Educational Status } \\
\hline Secondary or more & $84(32.8)$ & $172(67.2)$ & \multirow{2}{*}{$12.5(1)$} & \multirow{2}{*}{$<0.0001$} \\
\hline Religion & & & & \\
\hline Christianity & $76(26.0)$ & $216(74.0)$ & \multirow[t]{2}{*}{$0.06(1)$} & \multirow[t]{2}{*}{0.81} \\
\hline Islam & $46(27.1)$ & $124(72.9)$ & & \\
\hline \multicolumn{5}{|l|}{ Occupation } \\
\hline Non-skilled & $26(21.7)$ & $94(78.3)$ & \multirow{3}{*}{$1.8(2)$} & \multirow{3}{*}{0.4} \\
\hline Skilled & $18(29.0)$ & $44(71.0)$ & & \\
\hline Type of Marriage & & & & \\
\hline Monogamous & $104(28.0)$ & $268(72.0)$ & \multirow[t]{2}{*}{2.7} & \multirow[t]{2}{*}{0.10} \\
\hline Polygamous & $18(19.6)$ & $74(80.4)$ & & \\
\hline \multicolumn{5}{|l|}{ Level of Knowledge } \\
\hline poor knowledge & $89(23.7)$ & $286(76.3)$ & \multirow[t]{2}{*}{6.6} & \multirow[t]{2}{*}{0.01} \\
\hline good knowledge & $33(37.1)$ & $56(62.9)$ & & \\
\hline
\end{tabular}


Table 5. Multiple regression analysis assessing association between socio-demographic variables and study variables determining role of men in family planning among married nen in Gambari Village, Surulere Local Government Area, Oyo State, Nigeria.

\begin{tabular}{|c|c|c|c|c|c|}
\hline Variables & $\begin{array}{l}\text { Overall Knowledge } \\
\mathrm{N}=464\end{array}$ & $\begin{array}{l}\text { Overall attitude } \\
\mathrm{N}=464\end{array}$ & $\begin{array}{l}\text { Ever used } \\
\text { Contraceptive } N=464 \\
\end{array}$ & $\begin{array}{l}\text { Spouse ever used } \\
\text { contraceptive } N=464\end{array}$ & $\begin{array}{l}\text { Preference for } \\
\text { large family } N=464\end{array}$ \\
\hline & OR (CI) & OR (CI) & OR (CI) & OR (CI) & OR (CI) \\
\hline Age & $1.03(1.004-1.05) *$ & $0.99(0.97-1.004)$ & $0.97(0.95-0.99)^{* *}$ & $1.07(0.68-1.73)$ & $1.00(0.98-1.01)$ \\
\hline \multicolumn{6}{|l|}{ Religion } \\
\hline Christian (REF) & 1.00 & 1.00 & 1.00 & 1.00 & 1.0 \\
\hline $\begin{array}{l}\text { Muslim } \\
\text { Marriage type }\end{array}$ & $0.7(1.35-4.26)$ & $0.78(0.52-1.17)$ & $1.25(0.79-2.0)$ & $1.28(0.84-1.96)$ & $0.53(0.36-0.80) * *$ \\
\hline Monogamous (REF) & 1.00 & 1.00 & 1.00 & 1.00 & 1.00 \\
\hline $\begin{array}{l}\text { Polygamous } \\
\text { Education }\end{array}$ & $0.86(0.40-1.2)$ & $0.97(0.59-1.60)$ & $0.68(0.37-1.23)$ & $0.71(0.41-1.2)$ & $0.8(0.49-1.31)$ \\
\hline $\begin{array}{l}\text { Less than secondary school } \\
\text { education (REF) }\end{array}$ & 1.00 & 1.00 & 1.00 & 1.0 & 1.00 \\
\hline $\begin{array}{l}\text { Secondary education or more } \\
\text { Occupation }\end{array}$ & $2.41(1.36-4.26) * *$ & $1.61(1.07-2.44)^{*}$ & $2.0(1.22-3.3)^{* *}$ & $1.47(0.95-2.28)$ & $1.34(0.88-2.04)$ \\
\hline Non-skilled (REF) & 1.00 & 1.00 & 1.00 & 1.00 & 1,00 \\
\hline Semi-skilled & $1.02(0.55-1.89)$ & $1.29(0.82-2.03)$ & $0.99(0.58-1.7)$ & $1.21(0.74-1.97)$ & $0.75(0.48-1.19)$ \\
\hline Professional & $1.79(0.81-3.94)$ & $2.02(0.98-4.13)$ & $0.92(0.43-2.0)$ & $0.78(0.38-1.63)$ & $0.73(0.37-1.46)$ \\
\hline
\end{tabular}

$\mathrm{REF}-$ Reference group $*=\mathrm{p}<0.05 * *=\mathrm{P}<0.01$

\subsection{Source of Contraceptive Methods}

About half of the men who have ever used family planning services got their contraceptive device from the Hospital or a Primary Health Centre within their locality. A quarter of them got theirs from a local medicine store while less than $10 \%$ get it from their friends.

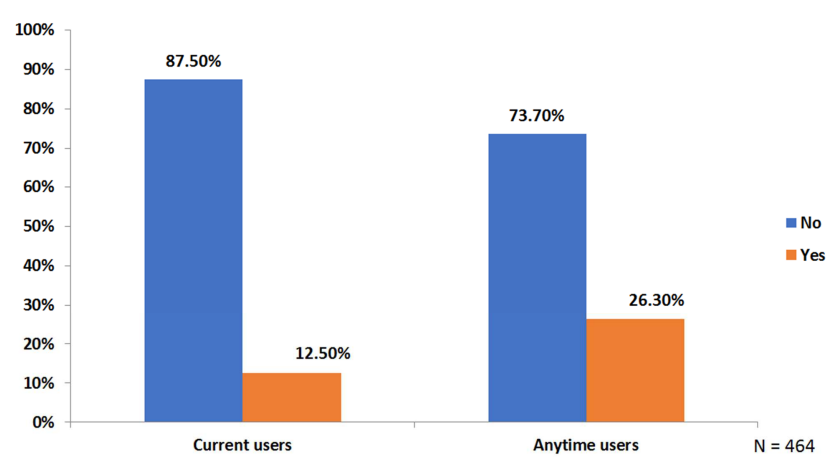

Figure 1. Use of Contraceptives among married men in Gambari Village, Surulere Local Government Area, Oyo State, Nigeria.

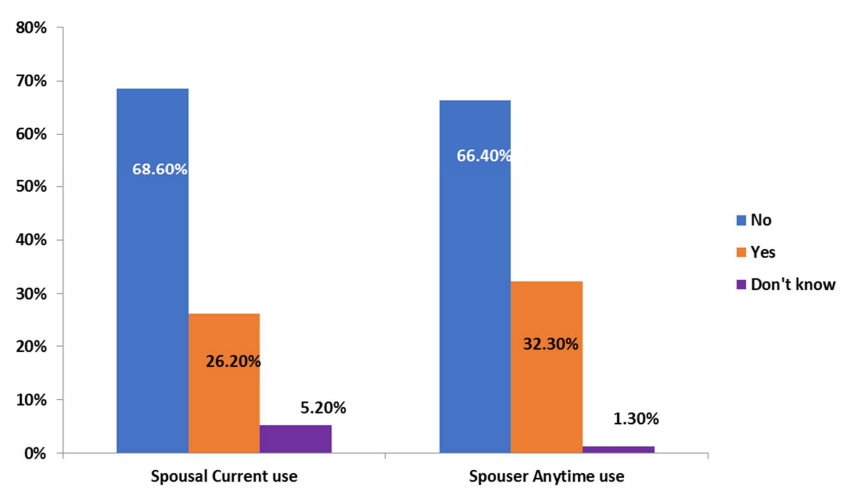

Figure 2. Reported Use of Contraceptives among Wives of respondents. among married men in Gambari Village, Surulere Local Government Area, Oyo State, Nigeria.

\subsection{Association Between Discussing Family Planning with Spouse (Wife) and Use of Contraceptives by Man or Spouse}

Fifty-nine percent (276) of men have discussed family planning with their wives, while $41 \%$ (188) have never opened or had such discussions. About $26 \%$ of interviewed men have ever used a male contraceptive device, while about half of this group $(12.5 \%)$ were current users. Similarly, only $32 \%$ of the men reported that their wives had ever used a modern contraceptive device while $26 \%$ reported wives as current users. A total $36 \%$ (102) of men who had ever discussed about family planning with their wives have used contraception, while only $10 \%$ (20) of those who never had such discussions have used contraception. This relationship was found to be statistically significant. $(\chi 2=40, \mathrm{p}<0.0001)$. Similarly, 52\% (144) of men who had ever discussed about family planning with their wives have wives who have ever used contraception, only six (3.2\%)) of those who have never had such discussions have wives who have ever used contraception. The relationship was also found to be statistically significant. $(\chi 2=123, \mathrm{p}<0.0001)$.

\subsection{Association Between Socio-demographic Characteristics and Use of Contraceptives}

A higher percentage of men who are less than 50 years $(31.9 \%)$ are more likely to have ever used modern contraceptive method compared to those who are older $(12.1 \%)$, and this association was found to be statistically significant. $\left(\chi^{2}=19.1, \mathrm{P}<0.0001\right)$ Men with at least secondary education or have a good knowledge of contraception had a statistically significant higher use of modern contraception than those with less than secondary education or those who have poor knowledge. Religion and occupation were not significantly associated with use of modern contraception among men. 


\subsection{Association Between Socio-demographic Variables and Study Variables Influencing the Role of Men in Family Planning}

Age was found to be a significant predictor of good knowledge of modern contraception and use of contraceptive device. Older men are more likely to have a better knowledge of contraceptive than younger men $(\mathrm{OR}=1.03, \mathrm{p}<0.05)$. With regards to use, younger men were more likely to have ever used modern contraception. ( $\mathrm{OR}=0.97, \quad \mathrm{CI}=0.95-0.99, \mathrm{p}$ $<0.005$ ). Education had a statistically significant relationship with knowledge, attitude and use of contraceptive methods among men. Men who had at least secondary education are likely to have better knowledge, attitude and uptake of family planning than men who have either primary education or are not educated. The regression analysis also showed that men who practice Islamic religion showed a preference for larger family than their Christian counterparts. $(\mathrm{OR}=0.53$, $\mathrm{CI}=0.4-0.8, \mathrm{p}<0.01)$.

\section{Discussion}

This study which sought to examine the role of men in family planning on the background of an African culture where it had been shown that the male is the dominant force for decision making in most marital relationships. Considering that a man cannot make a sound decision outside his level of knowledge, the study focused on level of knowledge, positivity of attitude, previous use of contraception, spouse's use of contraception and preference for large family as factors which determined the role of men in family's uptake of family planning.

The awareness of modern contraceptives in the community is very similar to $98.2 \%$ reported from a national survey. [6] It is also similar to many local studies which reported up to $99 \%$ awareness in Nigeria and other African countries. [2] The Injectable contraceptive was the highest known modern contraceptive method among the study population followed by the male condom which is different from other Nigerian and African studies, $[1,2,6]$ which found the male condom as the highest known contraceptive. This might be due to the way information was obtained in this study without prompting. Other local studies also showed that other contraceptive methods are not as popular with men. [1] This means a woman's choice of contraceptive may be limited if the husband is not sufficiently educated and the woman ends up following the husband's preference which may not be the best option at the time. Low level of awareness by men, of other modern contraceptive methods and its side effects may also lead to high discontinuation rate which was evident in the studies community by a wide difference between those who have ever used contraceptives and those who are current users. This wide difference was also reported other studies. [1]

The level of positive attitude towards family planning was rather higher than expected when this was compared to low contraceptive uptake by men and their spouses. This is corroborated by other studies, $[1,2]$ however, another study in
Nigeria had reported a lower value of $26 \%$ men who approved of going with their wives to family planning clinic, which is much lower than $73.7 \%$ reported in this study. [16] This difference might be because this study was in a rural location compared with the contrasting report which was from a semi-urban setting. In addition, men's preference for a large family, a reason why most men do not use modern contraceptive method was corroborated by other studies in Africa and Nigeria. [22] Older men were less likely to use modern contraceptive than younger men. This may be due to power imbalance between older men who marry much younger wives. [14] Such wives may lack the will (as occasioned by culture), or empowerment to negotiate effectively with their husbands who may have poor knowledge about contraceptive. [23, 24]

This study showed that education was significantly associated with men's overall knowledge, attitude and use of modern contraception, thereby improving their roles in family planning. Men with secondary or tertiary education are more likely to participate in family planning, or positively influence their spouses towards better uptake of modern contraception. This finding was similar to reports from other studies within Nigeria and Africa, $[6,16]$ but different from a study from Ibadan, Nigeria which reported primary education as significant predictor of use of contraceptive. [25] This might be due to the presence of many donor-funded reproductive health programmes in the state which might have targeted and changed the behaviour of the least educated people in the community.

\section{Conclusion}

The awareness of modern contraceptives among men in the study population is very low especially knowledge about contraceptive methods that are available for women, its side effects and the causes of contraceptive failures. There is a significant association between men's educational status and their level of knowledge about contraceptives. This low level of knowledge might not allow men to have a free discussion with their wives on family planning, even though this study showed a significant association between couple's discussion about family planning and use of contraceptives by the man or his spouse.

There is a wide dichotomy between attitude towards family planning and uptake of family planning in this population. This difference may be due to socio-cultural perception, a higher need for spacing than limiting pregnancy or failure of supply level activities within rural communities.

Men's role in family can improve family planning adoption if they have better knowledge about contraceptives, match their attitudes with corresponding action, and if they are able to have discussions with their spouses on family planning issues.

\section{Recommendations}

Family planning programs should target both men, women and couples. This may stop the erroneous perception in the 
community that family planning is a women-only affair.

Massive investment in education of young boys and girls may be the best investment towards improving reproductive health outcomes in sub-Saharan Africa. While this is a long-term investment, the effect will be felt by generations yet unborn.

A qualitative study is needed to investigate reasons for a wide gap between attitude towards family planning and uptake of family planning by men and their spouse.

\section{References}

[1] Adelekan A, Omoregie P, Edoni E. Male Involvement in Family Planning: Challenges and Way Forward. Int J Popul Res. 2014; 2014: 1-9.

[2] Vouking MZ, Evina CD, Tadenfok CN. Male involvement in family planning decision making in sub-Saharan Africa- what the evidence suggests. Vol. 19, Pan African Medical Journal. African Field Epidemiology Network; 2014.

[3] Alkema L, Kantorova V, Menozzi C, Biddlecom A. National, regional, and global rates and trends in contraceptive prevalence and unmet need for family planning between 1990 and 2015: A systematic and comprehensive analysis. Lancet. 2013; 381 (9878): 1642-52.

[4] United Nations (DESA). Global progress in satisfying the need for family planning. 2019.

[5] World Health Organization. Maternal mortality [Internet]. 2019 [cited 2020 Mar 10]. p. 1-5. Available from: www.who.int/news-room/fact-sheets/detail/maternal-mortality.

[6] National Population Commission. Nigeria demographic and health survey 2018 Key Indicators Report...., MD: National Population Commission and ORC .... 2019.

[7] Austin A. Unmet contraceptive need among married Nigerian women: An examination of trends and drivers. Contraception. 2015 Jan 1; 91 (1): 31-8.

[8] National Populations Commission (NPC) Nigeria \& ORC Macro Nigeria Demographic and Health Survey 2013. National Population Commission Federal Republic of Nigeria. 2014.

[9] Speizer IS, Calhoun LM, Hoke T, Sengupta R. Measurement of unmet need for family planning: Longitudinal analysis of the impact of fertility desires on subsequent childbearing behaviors among urban women from Uttar Pradesh, India. Contraception. 2013; 88 (4).

[10] Sinai I, Omoluabi E, Jimoh A, Jurczynska K. Unmet need for family planning and barriers to contraceptive use in Kaduna, Nigeria: culture, myths and perceptions. Cult Health Sex. 2019 Oct $29 ; 1-16$

[11] Croce-Galis M, Salazar E, Lundgren R. Male Engagement in Family Planning: Reducing Unmet Need for Family Planning by Addressing Gender Norms. 2014.
[12] Aliyu AA. Family Planning Services in Africa: The Successes and Challenges. In: Family Planning. 2018. p. 69.

[13] Starbird E, Norton M, Marcus R. Investing in family planning: Key to achieving the sustainable development goals. Vol. 4, Global Health Science and Practice. Johns Hopkins University Press; 2016. p. 191-210.

[14] Okwor EU, Olaseha IO. Married Men's Perception about Spousal Use of Modern Contraceptives: A Qualitative Study in Ibadan Northwest Local Government Area, Southwest Nigeria. Int Q Community Health Educ. 2010 Oct 22; 30 (3): 223-38.

[15] Wulifan JK, Mazalale J, Kambala C, Angko W, Asante J, Kpinpuo S, et al. Prevalence and determinants of unmet need for family planning among married women in Ghana-a multinomial logistic regression analysis of the GDHS, 2014. Contracept Reprod Med. 2019 Dec 30; 4 (1): 2.

[16] Ijadunola $\mathrm{M}$, Abiona $\mathrm{T}$, Ijadunola $\mathrm{K}$, Afolabi O, Esimai O, OlaOlorun F. Male Involvement in Family Planning Decision Making in Ile-Ife, Osun State, Nigeria. Afr J Reprod Health. 2010; 14 (4).

[17] Speizer IS, Corroon M, Calhoun L, Lance P, Montana L, Nanda $\mathrm{P}$, et al. Demand generation activities and modern contraceptive use in urban areas of four countries: A longitudinal evaluation. Glob Heal Sci Pract. 2014 Dec 1; 2 (4): 410-26.

[18] Kana MA, Tagurum YO, Hassan ZI, Afolanranmi TO, Ogbeyi GO, Difa JA, et al. Prevalence and determinants of contraceptive use in rural Northeastern Nigeria: Results of a mixed qualitative and quantitative assessment Musa. Ann Niger Med. 2016; 10 (1): 3-10.

[19] Tuloro T, Deressa W, Ali A, Health GD-EJ of, 2006 undefined. The role of men in contraceptive use and fertility preference in Hossana Town, southern Ethiopia. ajol.info.

[20] National Bureau of Statistics. Nigeria Census 2006 [Internet]. 2006 [cited 2018 Oct 14]. Available from: http://nigeria.opendataforafrica.org/apps/atlas/Osun/15-19.

[21] Rodríguez del Águila MM, González-Ramírez AR. Sample size calculation. Allergol Immunopathol (Madr). 2014; 42 (5): 485-92.

[22] Kassa M, Abajobir AA, Gedefaw M. Level of male involvement and associated factors in family planning services utilization among married men in Debremarkos town, Northwest Ethiopia. BMC Int Health Hum Rights. 2014; 14 (1): 33.

[23] Mosha I, Ruben R, Kakoko D. Family planning decisions, perceptions and gender dynamics among couples in Mwanza, Tanzania: A qualitative study. BMC Public Health. 2013; 13 (1): 523

[24] Corroon M, Speizer IS, Fotso JC, Akiode A, Saad A, Calhoun $\mathrm{L}$, et al. The role of gender empowerment on reproductive health outcomes in urban nigeria. Matern Child Health J. 2014; 18: $307-15$.

[25] Sekoni OO, Oladoyin VO. Determinants of family planning uptake among men in Ibadan, Nigeria. J Community Med Prim Heal Care. 2016; 28 (1): 38-44-44. 